\title{
Interest Rate Expectations Versus Forward Rates: Evidence From an Expectations Survey
}

\author{
BENJAMIN M. FRIEDMAN*
}

FOLLOWING HICKS [9] AND LUTZ [11], economists have developed a substantial literature relating the forward interest rates implied by currently prevailing rates on debts of differing maturity to market participants' expectations of interest rates in the future. Hicks suggested that implied forward rates might differ from the corresponding expected future rates by a liquidity premium, or term premium, and more recently Stiglitz [19] and others have formalized how market participants' risk aversion would give rise to such a premium. While in principle the premium could be either positive or negative, the usual upward slope of the yield curve suggests a positive premium that itself varies positively with the debt's term to maturity. Kessel [10] subsequently suggested that the premium for a given maturity might vary with real economic activity, and Culbertson [2] argued that relative outside debt supply quantities should alss affect the premium. More recently Nelson [16] offered an explanation for the premium even in the absence of risk aversion, and Friedman [5] related changes in the premium to shifts in wealth ownership among heterogenous investors.

An accompanying empirical literature has repeatedly tested each of these various hypotheses about forward rates and expected future rates, but usually with somewhat inconclusive results. A key reason for the weakness of much of this empirical literature has been the absence of independent information about market participants' expectations. Not surprisingly, the very early attempts based on the assumption of perfect foresight were most unsuccessful and this approach quickly went out of fashion. The traditional procedure since then has been either to apply the Hicks-Lutz theory to derive expectations proxies from the same term-structure data that generate the forward rates, or to use some other device like autoregressive or 'rational' expectations proxies. In either case, any hypothesis submitted to statistical testing is necessarily a joint hypothesis embodying both the relation of forward rates to expectations and the formation of expectations themselves. Failure of the hypothesis to conform to the data may then indicate rejection of the proposition relating forward rates to expectations, or rejection of the identifying restrictions imposed to derive the expectations proxy (or both).

The object of this paper is to test several familiar hypotheses about the relationship between the forward rates implied by the term structure and interest

* Harvard University. I am grateful to Angelo Melino for research assistance and helpful discussions, and to the National Science Foundation and the Alfred P. Sloan Foundation for research support. In addition, I am especially grateful to Peter Nagan, of The Goldsmith-Nagan Bond and Money Market Letter, for supplying his data and giving his permission for me to use them in this analysis. 
rate expectations, using the one ongoing systematic survey that samples market participants' expectations. The substitution of survey data for overidentified constructions removes the principal source of ambiguity that has plagued much of the earlier empirical literature of the term structure. Nevertheless, because of limitations in the available data, it is possible to perform these tests only for the very short end of the maturity spectrum.

Section I briefly describes the nature of the interest rate expectations survey and the calculation of the forward rate series from observed term structure data. Sections II-V present the results of testing the hypotheses that the implied term premium is zero on average (II), that it varies systematically with interest rate levels (III), that it varies with outside asset supplies (IV), and that it varies with economic activity (V). Section VI summarizes the findings of these tests and discusses their implications.

\section{The Survey Data and the Forward Rates}

The Goldsmith-Nagan Bond and Money Market Letter is a biweekly publication circulated widely among professional financial market participants including investors, traders and underwriters. Since September, 1969, the Goldsmith-Nagan Letter has conducted a quarterly survey of the interest rate expectations of a selected panel of approximately fifty of its subscribers who are known to the publisher to be market professionals. The survey, conducted at the end of each calendar quarter, asks respondents to indicate their respective point expectations for each of a set of interest rates as of the close of the last business day of the coming quarter and of the quarter following. The two expectations series exploited here, below denoted $R^{E 1}$ and $R^{E 2}$, consist of the pairs of means of the survey respondents' simultaneously held one-quarter-ahead and two-quarters-ahead expectations of the 3-month U.S. Treasury bill rate. ${ }^{1}$

Following Hicks, the forward rate of interest implied for one-period debts one period hence is

$$
F_{1}=\frac{\left(1+R_{2}\right)^{2}}{\left(1+R_{1}\right)}-1
$$

where $R_{1}$ and $R_{2}$ are the currently prevailing (spot) interest rates on one-period and two-period debts, respectively. Similarly, the forward rate implied for oneperiod debts two periods hence is

$$
F_{2}=\frac{\left(1+R_{3}\right)^{3}}{\left(1+R_{2}\right)^{2}}-1
$$

where $R_{3}$ is analogously the prevailing rate on three-period debts. The forward rates used below are constructed according to (1) and (2) from the observed market rates on 3-, 6- and 9-month Treasury bills as of the close of the last business day of each calendar quarter.

' See Friedman [6] for an analysis of the statistical properties of these expectations as well as those for five other interest rates. See Prell [18] for a more detailed description of the survey data. 
The data consist of thirty-one quarterly observations beginning in September, 1969. In all cases the reported discounted bill rates are adjusted to a couponequivalent yield basis.

\section{Is There a Term Premium?}

Whether implied forward interest rates are or are not identical to expected future interest rates has been a major question in monetary economics, for several good reasons. At the theoretical level the presence or absence of a term premium bears importantly on the appropriateness of treating all interest-bearing assets as perfect substitutes, a key turning point for a number of fundamental issues in monetary theory. ${ }^{2}$ At the empirical level, it is necessary to face the same question in determining how far to disaggregate among securities in estimating asset demand behavior. At the policy level, the usefulness of debt management policy (or the surrogate "Operation Twist" in the early 1960s), or the appropriateness of the old "bills only" approach to open market operations, again depends on asset substitutability properties to which a term premium (or its absence) provides important clues. ${ }^{3}$

Among the early tests for a term premium between interest rates on debts of different maturities, perhaps the best known is Meiselrnan's [12] work which used a simple error-learning hypothesis to proxy the unobservable expectations. Meiselman was unable to reject the hypothesis of no term premium. By contrast, subsequent investigations of the term structure using more general expectations mechanisms-for example, the work of Modigliani and Sutch [14], Modigliani and Shiller [13], and Nelson [16]-typically has found evidence of a significant term premium. Indeed, among recent studies, even in those that find no evidence of a significant premium the conclusion often turns less on the mean estimate than on its standard error. ${ }^{4}$

Given the survey expectations data and the implied forward rate series described in Section I, it is straightforward to define the term premium relationship between 6 - and 3-month bills, and between 9- and 6-month bills, respectively, as

$$
\begin{aligned}
& T P_{1}=F_{1}-R^{E 1} \\
& T P_{2}=F_{2}-R^{E 2} .
\end{aligned}
$$

In words, $T P_{1}$ is the difference between the implied forward rate on one-period debts one period hence and the one-period rate that market participants expect to prevail one period hence; and $T P_{2}$ is the analogous difference for one-period debts two periods hence.

The sample-period means and standard deviations of the two term premium series are respectively $m\left(T P_{1}\right)=0.56 \%, m\left(T P_{2}\right)=0.59 \%, s\left(T P_{1}\right)=0.45 \%, s\left(T P_{2}\right)$ $=0.68 \%$. On the basis of this simple evidence, therefore, it is impossible to reject

${ }^{2}$ See, for example, Tobin [20], Brunner and Meltzer [1] and Friedman [3].

${ }^{3}$ See, for example, Tobin [21] and Modigliani and Sutch [14].

${ }^{4}$ Hamburger and Platt [8], for example, using data for 3-month and 6-month U.S. Treasury bills, estimated the equivalent of $-\alpha$ in (4) below to be $0.30 \%$. but with $t$-statistic only 1.1 . 
the null hypothesis of a zero term premium despite mean estimates that are relatively large in comparison to prevailing interest rate levels. ${ }^{5}$ From (1) and (3), for example, $T P_{1}=0.56 \%$ means that 6 -month rates will exceed 3 -month rates by approximately $0.28 \%$, even if the current 3 -month rate is expected to continue to prevail three months hence. Similarly, $T P_{2}=0.59 \%$ means that 9 -month rates will exceed 6 -month rates by approximately $0.20 \%$ even if the current 3 -month rate is expected to continue to prevail both three months hence and six months hence.

Simply looking at calculated means and standard deviations, however, is an incomplete way to test the hypothesis that the term premium as defined in (3) is zero. The proper test follows from relating the corresponding forward rates and expectations in the form

$$
F_{i}=\alpha+\beta R^{E i}+u_{i}
$$

where $u_{i}$ is a zero-mean finite-variance disturbance term which is uncorrelated with $R^{E i}$. The "pure expectations theory" of the term structure then corresponds to the null hypothesis

$$
H_{0}:(\alpha, \beta)=(0,1)
$$

(as well as lack of serial correlation in $u_{i}$ ).

The results of estimating (4) by ordinary least squares for the two data sets are

$$
\begin{aligned}
& F_{1}=-0.74+1.21 R^{E 1} \quad\left(\bar{R}^{2}=.94, S E=0.39 \%, D W=1.45\right) \\
& \text { (0.36) (0.06) } \\
& F_{2}=-1.66+1.36 R^{E 2} \quad\left(\bar{R}^{2}=.82, S E=0.61 \%, D W=1.32\right) \\
& \text { (0.73) } \quad(0.12)
\end{aligned}
$$

where $\bar{R}^{2}$ is the coefficient of determination adjusted for degrees of freedom, $S E$ is the standard error of estimate, $D W$ is the Durbin-Watson statistic, and the number in parentheses beneath each coefficient is its standard error. In both cases the results not only warrant rejecting the joint null hypothesis (5) but also (using a two-tailed $t$-test at the .05 significance level) warrant rejecting separately the individual hypotheses $\alpha=0$ and $\beta=1{ }^{6}$ Hence it is clear that the inability to reject the hypotheses $m\left(T P_{i}\right)=0$, as noted above, is due to the implicit imposition of $\beta=1$, a restriction which the data strongly reject. Indeed, in both data sets the estimated $\beta$ value is sufficiently greater than unity to render the estimated $\alpha$ value negative.

In sum, the evidence sharply rejects the "pure expectations" hypothesis that the market simply prices debts of different maturities so as to satisfy the HicksLutz condition with no term premium included. ${ }^{7}$

\footnotetext{
${ }^{5}$ The sample-period means of the observed interest rates on 3-, 6-, and 9-month bills are $m\left(R_{1}\right)=$ $6.13 \%, m\left(R_{2}\right)=6.44 \%$, and $m\left(R_{3}\right)=6.56 \%$.

${ }^{6}$ In addition, the results for $F_{2}$ reject at the .05 level the hypothesis of lack of serial correlation in $u_{2}$.

'An alternative interpretation of the data would be to take the forward rates as given and to ask whether the survey respondents, in forming their expectations, merely take the forward rate as the rate most likely to prevail. The data also warrant rejecting the null hypothesis (5) in the alternative formulation $R^{E^{r}}=\alpha+\beta F_{i}+u_{i}$.
} 


\section{Does the Term Premium Vary with Interest Rates?}

The rejection not only of $\alpha=0$ but also of $\beta=1$ in (4) immediately suggests that the term premium for a given maturity varies with the prevailing level of interest rates. Kessel first argued that the term premium is nonconstant, and, among subsequent more formal models of the term premium, several provide rationales for expecting the term premium to vary (usually positively) with interest rates.

The results of estimating by ordinary least squares the relationship

$$
T P_{i}=\alpha+\beta_{1} R_{i}+\beta_{2} R_{i, t-1}+u_{i}
$$

are

$$
\begin{aligned}
& T P_{1}=-0.77+0.04 R_{1}+0.18 R_{1, \ell-1} \quad\left(\bar{R}^{2}=.39, S E=0.37 \%, D W=1.90\right) \\
& \begin{array}{lll}
(0.31) & (0.08) & (0.07)
\end{array} \\
& T P_{2}=-1.04+0.28 R_{2}-0.04 R_{2, t-1} \quad\left(\bar{R}^{2}=.27, S E=0.55 \%, D W=1.74\right) \text {. } \\
& \begin{array}{lll}
(0.49) & (0.12) \quad(0.11)
\end{array}
\end{aligned}
$$

In both cases, at least one of the pair $\left(\beta_{1}, \beta_{2}\right)$ is significantly different from zero at the .05 level individually, and the associated $F$-statistics warrant rejecting the null hypothesis

$$
H_{0}: \beta_{1}=\beta_{2}=0
$$

at the .01 level. Analogous regressions of $T P_{1}$ on $R_{2}$, and $T P_{2}$ on $R_{1}$, yield roughly similar results.

In sum, the evidence strongly indicates that the market not only prices debts of different maturities so as to set forward rates not equal to expected future interest rates but also does so in a way that systematically varies with current interest rate levels.

\section{Does the Term Premium Vary with Outside Asset Supplies?}

In theories of asset pricing based on the equation of choice-theoretic market demands to exogenous outside supplies, the relationships among market-clearing asset prices (yields) typically vary with relative asset supplies. ${ }^{8}$ Under strong conditions describing market participants' willingness to substitute one asset for another, however, relative yields may be invariant to relative asset supplies. Given the government's ability to determine the maturity structure of the outstanding public debt via either debt management policy (the Treasury) or open market operations (the Federal Reserve), it is not surprising that several contributions to the previous empirical literature of the term structure have attempted to find evidence of an effect due to relative supplies of government securities of different maturities. ${ }^{9}$

\footnotetext{
${ }^{8}$ For the explicit derivation of such a model given the assumption of constant relative risk aversion, see Friedman [5].

${ }^{9}$ See, for example, Modigliani and Sutch [15], Okun [17], and Hambor and Weintraub [7]. With the exception of Okun's work, most such attempts have produced negative results. For evidence relating the market-clearing yield on inside assets (corporate bonds) to the amount supplied, see Friedman [4].
} 
Tests using survey data to define the term premium as above do not show strong evidence of systematic variation of the term premium with simple measures of the relative supplies of government securities. For the ratio of outstanding amounts of 3- and 6-month Treasury bills (RAT), for example, the ordinary leastsquares results are

$$
\begin{aligned}
& T P_{1}=-0.51+0.56 R A T \quad\left(\bar{R}^{2}=.04, S E=0.45 \%, D W=1.15\right) \\
& (0.70) \quad(0.36) \\
& T P_{2}=\underset{(1.03)}{-1.17}+\underset{(0.53)}{0.91 R A T} \quad\left(\bar{R}^{2}=.06, S E=0.67 \%, D W=1.46\right) .
\end{aligned}
$$

Here the coefficient on the ratio of outstandings is significantly different from zero at the .10 level but not the .05 level in the equation for the two-period-hence premium, and not even at the .10 level in the equation for the one-period-hence premium. Similarly, for the mean maturity of the entire outstanding Treasury debt $(M A T)$, the ordinary least-squares results are

$$
\begin{array}{cc}
T P_{1}=\underset{(0.64)}{0.26}+\underset{(0.017)}{0.008 M A T} \quad\left(\bar{R}^{2}=.03, S E=0.47 \%, D W=1.03\right) \\
T P_{2}=\underset{(0.94)}{-0.70}+\underset{(0.025)}{0.035 M A T} \quad\left(\bar{R}^{2}=.03, S E=0.68 \%, D W=1.31\right) .
\end{array}
$$

Here the coefficient on the mean maturity variable is significantly different from zero at the .10 level in neither equation. More complicated equations, relating the term premium to lagged values of the ratio or mean maturity variable, or to both at once, yield similarly negative results. ${ }^{10}$

In sum, the use of survey expectations instead of constructed expectations proxies does not yield evidence that the term premium at the very short end of the maturity spectrum varies systematically with the maturity structure of the outstanding U.S. Treasury securities.

\section{Does the Term Premium Vary with Economic Activity?}

The contributions of Kessel and others provide grounds for believing that the term premium will vary not only according to interest rate levels, as shown above, but also according to any of several dimensions of economic activity. Plausible examples of such variables in this context include the unemployment rate, the growth rate of real gross national product, and the rate of increase of prices (the GNP deflator), all as indicators of various cyclical aspects of economic activity. Additional plausible examples include the growth rate of the money stock $(M-1)$ and the federal government deficit, as indicators of monetary and fiscal policy, respectively.

Table 1 shows the results of estimating by ordinary least squares the relationship

${ }^{10}$ The joint relationship between $T P_{1}$ and the variable set $\left(R A T, R A T_{-1}, M A T, M A T_{-1}\right)$ does yield $F(4,25)=2.89$ versus a critical value of 2.76 at the .05 level; but one "significant" result in about twenty combinations is no sign of a genuine relation. 
Table 1

Tests for the Relation of the Term Premium with Economic Activity

\begin{tabular}{|c|c|c|c|c|c|c|c|}
\hline$X$ & $\alpha$ & $\gamma_{1}$ & $\gamma_{2}$ & $\bar{R}^{2}$ & $S E$ & $D W$ & $F(2,26)$ \\
\hline \multicolumn{8}{|c|}{$T P_{1}=\alpha+\gamma_{1} X+\gamma_{2} X_{t-1}+u$} \\
\hline$U$ & $\begin{array}{c}1.17 \\
(0.38)\end{array}$ & $\begin{array}{c}0.25 \\
(0.18)\end{array}$ & $\begin{array}{c}-0.36 \\
(0.17)\end{array}$ & .16 & $0.43 \%$ & 1.58 & $3.74^{b}$ \\
\hline$Y$ & $\begin{array}{c}0.69 \\
(0.09)\end{array}$ & $\begin{array}{r}-10.70 \\
(6.60)\end{array}$ & $\begin{array}{r}-13.53 \\
(6.60)\end{array}$ & .24 & $0.41 \%$ & 1.84 & $5.47^{b}$ \\
\hline$P$ & $\begin{array}{c}-0.20 \\
(0.20)\end{array}$ & $\begin{array}{c}38.88 \\
(18.29)\end{array}$ & $\begin{array}{c}8.31 \\
(18.26)\end{array}$ & .32 & $0.38 \%$ & 1.89 & $7.73^{*}$ \\
\hline$M$ & $\begin{array}{c}1.18 \\
(0.31)\end{array}$ & $\begin{array}{c}-23.79 \\
(18.57)\end{array}$ & $\begin{array}{c}-21.23 \\
(18.05)\end{array}$ & .09 & $0.45 \%$ & 1.36 & 2.33 \\
\hline$G$ & $\begin{array}{c}0.74 \\
(0.13)\end{array}$ & $\begin{array}{c}0.005 \\
(0.006)\end{array}$ & $\begin{array}{c}0.003 \\
(0.006)\end{array}$ & .08 & $0.45 \%$ & 1.19 & 2.23 \\
\hline \multicolumn{8}{|c|}{$T P_{2}=\alpha+\gamma_{1} X+\gamma_{2} X_{t-1}+u$} \\
\hline$U$ & $\begin{array}{c}1.20 \\
(0.56)\end{array}$ & $\begin{array}{c}0.28 \\
(0.26)\end{array}$ & $\begin{array}{c}-0.40 \\
(0.25)\end{array}$ & .07 & $0.63 \%$ & 1.70 & 2.08 \\
\hline$Y$ & $\begin{array}{c}0.68 \\
(0.14)\end{array}$ & $\begin{array}{r}-15.83 \\
(9.99)\end{array}$ & $\begin{array}{c}-9.58 \\
(9.99)\end{array}$ & .11 & $0.61 \%$ & 1.86 & $2.68^{c}$ \\
\hline$P$ & $\begin{array}{c}-0.34 \\
(0.31)\end{array}$ & $\begin{array}{c}11.03 \\
(27.66)\end{array}$ & $\begin{array}{c}44.45 \\
(27.61)\end{array}$ & .21 & $0.58 \%$ & 1.83 & $4.65^{b}$ \\
\hline$M$ & $\begin{array}{c}0.91 \\
(0.46)\end{array}$ & $\begin{array}{c}-12.78 \\
(27.73)\end{array}$ & $\begin{array}{c}-14.60 \\
(26.96)\end{array}$ & .05 & $0.66 \%$ & 1.55 & 0.39 \\
\hline$G$ & $\begin{array}{c}0.71 \\
(0.18)\end{array}$ & $\begin{array}{c}-0.003 \\
(0.008)\end{array}$ & $\begin{array}{c}0.011 \\
(0.008)\end{array}$ & .04 & $0.64 \%$ & 1.65 & 1.52 \\
\hline
\end{tabular}

Notes: $U=$ unemployment rate

$Y=$ growth rate of real income

$P=$ rate of increase of prices

$a$ significant at .01 level

$b$ significant at .05 level

$M=$ growth rate of money stock

c = significant at .10 level

$G=$ government deficit

$$
T P_{i}=\alpha+\gamma_{1} X+\gamma_{2} X_{t-1}+u_{i}
$$

where $X$ in turn represents each of these five variables. Especially for the oneperiod-ahead term premium, the $F$-statistics warrant rejecting the null hypothesis

$$
\text { . } H_{0}: \gamma_{1}=\gamma_{2}=0
$$

for the three indicators of overall economic activity. By contrast, the $F$-statistics do not warrant rejecting the null hypothesis for either economic policy indicator in the equation for either term premium.

On the surface it appears as if the results shown in Table 1 provide evidence relating the term premium to macroeconomic activity. Nevertheless, since the results presented in Section III above relate the term premium to interest rate levels, and since interest rate levels also vary systematically with economic activity, it is necessary to investigate further in order to unravel the effect of economic activity from the effect of interest rate levels. Table 2 presents $F$ statistics for separate tests of the null hypotheses (7) and (9), within the joint relationship 
Table 2

$F$-Statistics for Joint Relations

\begin{tabular}{ccc}
$T P_{1}=\alpha+\beta_{1} R_{1}+\beta_{2} R_{1, t-1}+\gamma_{1} X+\gamma_{2} X_{t-1}+u$ & \\
& $H_{0}: \beta_{1}=\beta_{2}=0$ & $H_{0}: \gamma_{1}=\gamma_{2}=0$ \\
$U$ & $5.27^{\mathrm{h}}$ & 0.70 \\
$Y$ & $4.43^{\mathrm{b}}$ & 1.33 \\
$P$ & 2.35 & 1.07 \\
$M$ & $7.24^{\mathrm{a}}$ & 0.95 \\
$G$ & $5.41^{\mathrm{b}}$ & 1.14 \\
$T P_{2}=\alpha+\beta_{1} R_{2}+\beta_{2} R_{2, l-1}+\gamma_{1} X+\gamma_{2} X_{t-1}+u$ & \\
\hline$X$ & $H_{0}: \beta_{1}=\beta_{2}=0$ & $H_{0}: \gamma_{1}=\gamma_{2}=0$ \\
$U$ & $5.24^{\mathrm{b}}$ & 1.49 \\
$Y$ & $6.02^{\mathrm{a}}$ & $2.67^{\mathrm{c}}$ \\
$P$ & 2.92 & 1.68 \\
$M$ & $5.88^{\mathrm{a}}$ & 0.43 \\
$G$ & $7.73^{\mathrm{a}}$ & 1.19 \\
\hline
\end{tabular}

Notes: See Table 1.

$$
T P_{i}=\alpha+\beta_{1} R_{i}+\beta_{2} R_{i, t-1}+\gamma_{1} X+\gamma_{2} X_{t-1}+u_{i},
$$

where $X$ in turn is each of the five economic activity variables considered in Table 1. For all variables except price inflation, the results make clear that the basic relation is between the term premium and interest rate levels, not economic activity, and that the appearance of a significant relation in Table 1 is due merely to the correlation between $X$ and $R ; X$ adds nothing significant to the explanation of the term premium after allowing for $R,{ }^{11}$ but $R$ does so after allowing for $X$. The price inflation variable and the (nominal) interest rate level are sufficiently correlated that neither adds anything significant after allowing for the other.

In sum, the evidence supports a relationship between the term premium and simple indicators of economic activity, but only to the extent that the term premium varies with interest rate levels, and interest rate levels in turn vary with economic activity. The evidence does not support a relationship between the term premium and simple indicators of economic policy.

\section{Concluding Remarks}

The statistical results assembled in this paper provide evidence disconfirming the "pure expectations theory" of the term structure of interest rates. The market does not price debts of different maturity so that implied forward rates are identical to expected future interest rates, but instead incorporates a positive term premium in rates on longer-term debts. Moreover, the premium for a given maturity varies positively with the level of prevailing interest rates. By contrast, the simple experiments reported here show no evidence of independent systematic variation of the term premium either with relative supplies of outside assets or with familiar indicators of economic activity and monetary and fiscal policy.

\footnotetext{
"The effect of $Y$ in the equation for $T P_{2}$ is an exception, but one in ten at the 10 level again constitutes no genuine evidence.
} 
These results are highly limited, of course, in that they focus only on the very short end of the debt maturity spectrum-only out to nine months. Nevertheless, they provide new information bearing on familiar questions, and they suggest the usefulness of exploiting survey data on expectations whenever such data are available.

\section{REFERENCES}

1. Karl Brunner and Allan H. Meltzer. "Money, Debt and Economic Activity." Journal of Political Economy, LXXX (September/October, 1972).

2. J. M. Culbertson. "The Term-Structure of Interest Rates." Quarterly Journal of Economics, LXXI (November, 1957).

3. Benjamin M. Friedman. "The Theoretical Nondebate About Monetarism."Kredit und Kapital, IX (No. 3, 1976).

4. Benjamin M. Friedman. "Financial Flow Variables and the Short-Run Determination of LongTerm Interest Rates.” Journal of Political Economy, LXXXV (August, 1977).

5. Benjamin M. Friedman. "The Effects of Shifting Wealth Ownership on the Term Structure of Interest Rates." Quarterly Journal of Economics, forthcoming.

6. Benjamin M. Friedman. "Survey Evidence on the 'Rationality' of Interest Rate Expectations." Journal of Monetary Economics, forthcoming.

7. John C. Hambor and Robert E. Weintraub. "The Term Structure: Another Look." Journal of Money, Credit and Banking, VI (November, 1974).

8. Michael J. Hamburger and Elliott Platt. "The Expectation Hypothesis and the Efficiency of the Treasury Bill Market." Review of Economics and Statistics, LVII (May, 1975).

9. John R. Hicks. Value and Capital (London: Oxford University Press, 1939).

10. Reuben A. Kessel. "The Cyclical Behavior of the Term Structure of Interest Rates." Guttentag (ed.), Essays on Interest Rates, Vol. II (New York: Columbia University Press, 1971).

11. Friedrich A. Lutz. "The Structure of Interest Rates." Quarterly Journal of Economics, LIV (November, 1940).

12. David Meiselman. The Term Structure of Interest Rates (Englewood Cliffs: Prentice-Hall, 1962).

13. Franco Modigliani and Robert J. Shiller. "Inflation, Rational Expectations, and the Term Structure of Interest Rates." Economica, XL (February, 1973).

14. Franco Modigliani and Richard Sutch. "Innovations in Interest Rate Policy." American Economic Review, LVI (May, 1966).

15. Franco Modigliani and Richard Sutch. "Debt Management and the Term Structure of Interest Rates: An Empirical Analysis of Recent Experience." Journal of Political Economy, LXXXV (August, 1967).

16. Charles R. Nelson. The Term Structure of Interest Rates (New York: Basic Books, 1972).

17. Arthur M. Okun. "Monetary Policy, Debt Management, and Interest Rates: A Quantitative Appraisal." Commission on Money and Credit, Stabilization Policies (Englewood Cliffs: Prentice-Hall, Inc., 1963).

18. Michael J. Prell. "How Well Do the Experts Forecast Interest Rates?" Federal Reserve Bank of Kansas City, Monthly Review (September, 1973).

19. J. E. Stiglitz. "A Consumption-Oriented Theory of the Demand fo $r$ Financial Assets and the Term Structure of Interest Rates." Review of Economic Studies, XXXVII (July, 1970).

20. James Tobin. "Money, Capital and Other Stores of Value." American Economic Review, LI (May, 1961).

21. James Tobin. "An Essay on the Principles of Debt Management." Commission on Money and Credit, Fiscal and Debt Management Policies (Englewood Cliffs: Prentice-Hall, Inc., 1963). 